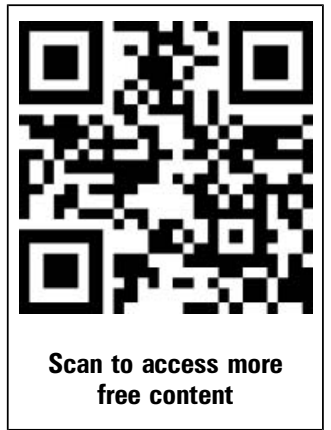

${ }^{1}$ Senior Advisor, East European Institute for Reproductive Health, Tirgu-Mures, Romania

${ }^{2}$ Epidemiologist, Department of Obstetrics, Gynecology, and Reproductive Sciences, University of California, San Francisco, CA, USA

${ }^{3}$ Bixby Professor, Bixby Center for Population, Health and Sustainability, University of California, Berkeley, CA, USA

\section{Correspondence to}

Dr Mihai Horga, East European Institute for Reproductive Health, 1 Moldovei Street, Tirgu-Mures 540493, Romania; mhorga@eeirh.org

Received 23 September 2012 Revised 25 October 2012 Accepted 26 October 2012
To cite: Horga M, Gerdts C, Potts M. Journal of Family Planning and Reproductive Health Care 2013, 39, 2-4.

\title{
The remarkable story of Romanian women's struggle to manage their fertility
}

\author{
Mihai Horga, ${ }^{1}$ Caitlin Gerdts, ${ }^{2}$ Malcolm Potts ${ }^{3}$
}

\section{BACKGROUND}

In 1957, along with many countries in Eastern Europe, Romania liberalised its abortion law. The Soviet model of birth control made surgical abortion easily available, but put restrictions on access to modern contraceptives, leading to an exceptionally high abortion rate. By the mid-1960s there were 1100000 abortions performed each year in Romania, a lifetime average of 3.9 per woman, the highest number ever recorded. ${ }^{1}$ In October 1966, 1 year after coming to power, in an attempt to boost fertility, Romania's communist leader Nicolae Ceausescu made abortion broadly illegal, permitting the procedure legally only under a narrow range of circumstances: for women with four or more children, over the age of 45 years, in circumstances where the pregnancy was the result of rape or incest or threatened the life of the women, or in the case of congenital defect. ${ }^{1}$

Just months after abortion was restricted, the number of safe, registered abortions had fallen 20 -fold, and 1 year after the law took effect, the total fertility rate (TFR) nearly doubled (from 1.9 just before the restrictive law to 3.6 in 19671968). As women gradually found solutions for regulating their fertility - either through contraceptives procured illegally or through illegal abortions - the TFR began to fall again, reaching 2.9 in 1970 , 2.2 in 1980-1984 and stabilised around 2.3 births per woman during the period 1985-1989. ${ }^{12}$

At the same time deaths from unsafe abortion rose rapidly. Between 1966 and 1989, while abortion was illegal in Romania, overall maternal mortality increased dramatically, from 85 per 100000 live births in 1965 to a peak of 169 per 100000 live births in 1989. ${ }^{1}$ Over the same period, maternal mortality from unsafe abortion skyrocketed to an incredible 147 per 100000 live births, while maternal deaths from other obstetric causes continued to decline. Figure 1 illustrates the peak and plateau in total fertility, along with the striking rise in maternal mortality that was solely driven by abortion-related deaths, as maternal deaths from other obstetric causes continued to fall.

\section{SHIFT IN FAMILY PLANNING POLICY}

Within days of the fall of Ceausescu's regime in December 1989, the antiabortion law was abolished and abortion made available on request. Within the span of 1 year, the maternal mortality rate fell by half to 84 per 100000 live births. In the absence of contraceptive services, commodities and information, the number of safe, registered abortions again rose dramatically. ${ }^{3}$ In 1990, 913973 registered abortions were performed, and 314746 births were recorded: a three to one ratio. ${ }^{5}$ Initially, contraception use was slow to catch on. ${ }^{6}$ Traditional contraceptive methods were common, but modern methods became quickly and widely available through international donations and in pharmacies. A network of family planning clinics was developed in the mid-1990s and physicians were trained to provide family planning. Family planning services were included in primary health care, and modern contraceptives were made available free of charge to vulnerable groups of the population, resulting in increased contraceptive use. ${ }^{7} 8$ According to the latest survey, contraceptive prevalence in Romania is above $70 \%$, modern contraceptive prevalence accounts for $61.1 \%$ and the most used methods are condoms (27.6\%), pills (22.8\%) and intrauterine devices $(7.0 \%){ }^{9}$

After a drop from 2.2 in 1989 to 1.8 in 1990 and to 1.4 in 1993-1994, the TFR in Romania has remained constant at 


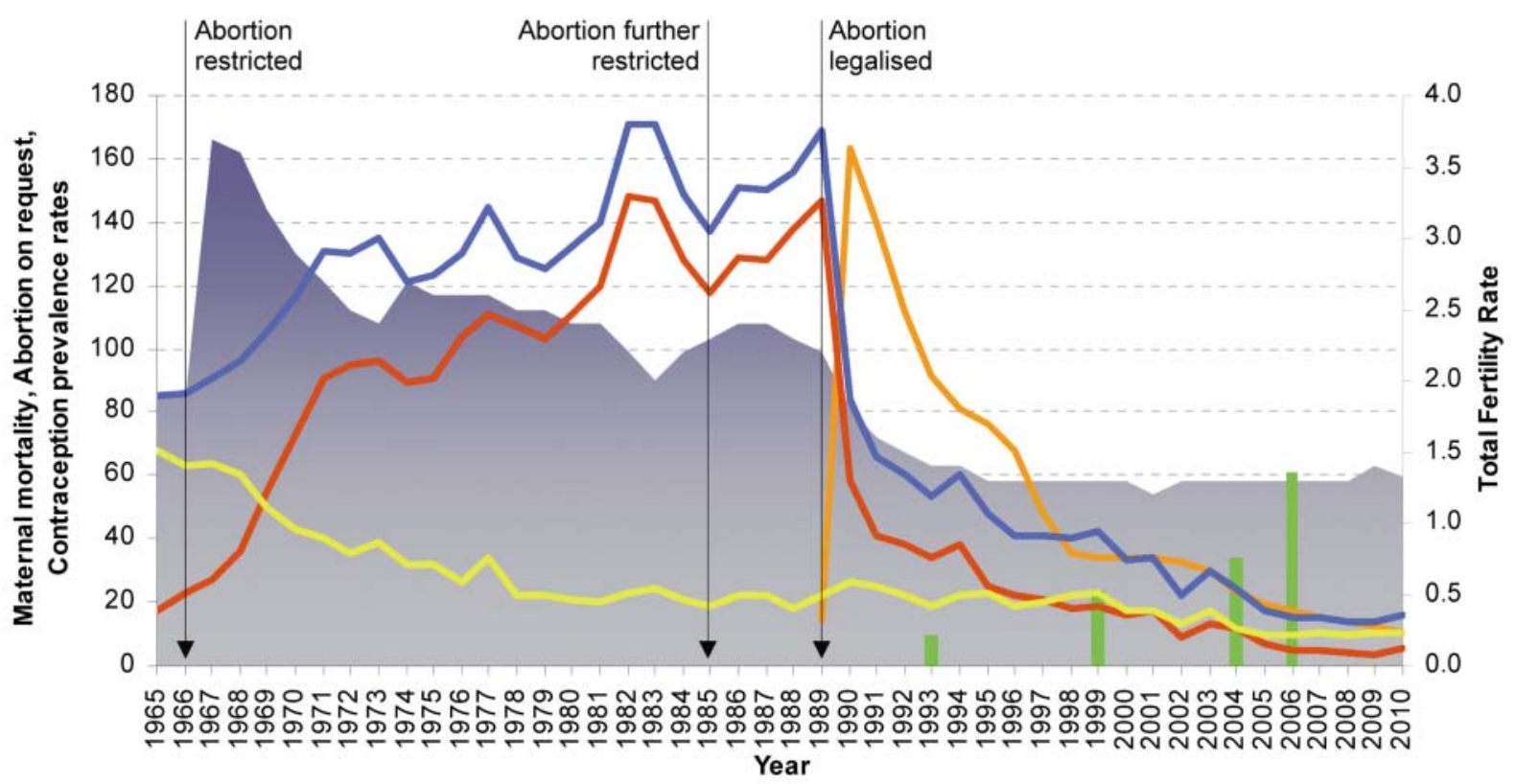

Total fertility rate

Modern contraceptive prevalence rate (\%)

Maternal mortality rate due to direct causes (per 100000 live births)

Abortion on request rate (per 1000 women)

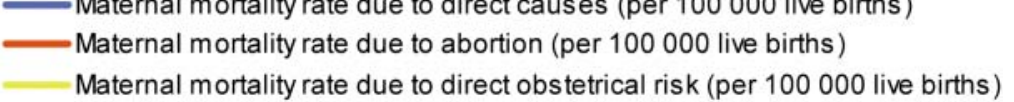

Figure 1 Abortion, contraception, maternal mortality and fertility in Romania during the period 1965-2010.

$1.3,{ }^{2}$ despite the marked rise in contraceptive prevalence. This rise in contraceptive use has been accompanied by a decisive fall in the induced abortion rate from 163.6 per 1000 women in 1990 to 10.1 in 2010 and in the abortion-related maternal mortality rate from 147 per 100000 live births in 1989 to 5.2 in 2010..$^{5}$ Figure 1 shows a combined view of abortion, contraception, maternal mortality and TFRs for the 20 years following the change in abortion legislation.

As has been suggested elsewhere, ${ }^{10}$ there may be a number of plausible explanations for such a dramatic drop in the abortion rate, including increased contraceptive effectiveness, and shifting attitudes about the acceptability of abortion which could decrease women's willingness to report abortions. Indeed, many factors may have contributed to decreases in induced abortions. However, although we cannot directly attribute causality, we have no data to suggest that there was a decline in the completeness of reporting abortion experiences in successive surveys. The marked rise in contraceptive prevalence coinciding with a dramatic decline in the abortion rate makes increased modern contraceptive use the most likely explanation for the steeply falling abortion rate in Romania.

\section{LESSONS LEARNED}

Few countries in history have made such dramatic shifts in family planning policy or availability that would allow the study of causal links between access to contraception and abortion and changes in reproductive outcomes. While the fertility patterns illustrated by the Romanian example highlight the complex nature of fertility and its determinants, two points emerge clearly. First, restricting access to safe abortion in Romania caused a dramatic increase in maternal mortality driven solely by unsafe abortionrelated deaths. And second, increased access to modern contraception in Romania over the last 15 years has not reduced fertility in the country, but instead has reduced the need for women to resort to abortion. Countries that increasingly seek to restrict access to abortion and contraception should look and learn from Romania's example.

Acknowledgements The authors wish to thank Dr Martha Campbell for her guidance and invaluable perspective.

Funding None.

Competing interests None.

Provenance and peer review Not commissioned; externally peer reviewed.

\section{REFERENCES}

1 Teitelbaum M. Fertility effects of the abolition of legal abortion in Romania. Popul Stud 1972;26:405-417.

2 Romanian National Institute of Statistics. Statistical Yearbook 2010. 2012. http://www.insse.ro/cms/rw/pages/ anuarstatistic2010.en.do [accessed 2 September 2012].

3 Johnson BR, Horga M, Andronache L. Contraception and abortion in Romania. Lancet 1993;341:875-878.

4 Serbanescu F, Morris L, Stupp P, et al. The impact of recent policy changes on fertility, abortion, and contraceptive use in Romania. Stud Fam Plann 1995;26:76-87. 
5 Romanian Ministry of Health, National Institute for Public Health, National Center for Statistics and Informatics in Public Health. Yearly bulletins on main health indicators and on maternal mortality. http://www.ccss.ro/public_html/?q=content/ date-statistice-0 [accessed 2 September 2012].

6 Romanian Ministry of Health, Institute for Mother and Child Care, Division of Reproductive Health, Centers for Diseases Control and Prevention. Romania: Reproductive Health Survey, 1993. Final Report. 1995.

7 Romanian Association of Public Health and Health Management, School of Public Health, University of Medicine and Pharmacy "Carol Davila", National Commission for
Statistics, Division of Reproductive Health, Centers for Diseases Control and Prevention, USAID, UNFPA, UNICEF. Romania: Reproductive Health Survey, 1999. Final Report. 2001.

8 Romanian Ministry of Health, World Bank, UNFPA, USAID, UNICEF. Romania: Reproductive Health Survey, 2004. Summary Report. 2005.

9 UNFPA, Max Plank Institute for Demographic Research, National Institute of Statistics. Romania Gender and Generations Survey. First Wave Report. 2007.

10 Sedgh G, Singh S, Shah IH, et al. Induced abortion: incidence and trends worldwide from 1995 to 2008. Lancet 2012;379:625-632. 